\title{
ERRATUM STATEMENT
}

Vol. 10, No. 3, August 1977

"Studies on the mechanism of pathogenicity of Neisseria gonorrhoeae", by P. Novotny et al.

Page 356, Line 20

... containing $5 \mathrm{~m}$.moles of colchicine. This should be ... containing $5 \mu$. moles of colchicine. 